\title{
O Teatro Rapsódico em miúdos
}

\author{
RAILSON GOMES ALMEIDA
}

Railson Gomes Almeida é ator, dramaturgo e pesquisador teatral. É bacharel e licenciando em Teatro pela UFPB e mestrando em Artes Cênicas pela UFRN. Dedica-se a pesquisa de dramaturgia contemporânea e tem estudado as teorias de Jean-Pierre Sarrazac e observado suas convergências com o teatro brasileiro; pesquisa também o educador Paulo Freire e manifestações do seu pensamento nas artes cênicas. Tem experiência com interpretação em diferentes âmbitos das artes cênicas e com a escrita de peças teatrais.

AFILIAÇÃO - Universidade Federal do Rio Grande do Norte (UFRN) - Natal - Brasil Lattes: http://lattes.cnpq.br/0917673078409863

ouvirouver Uberlândia v. 15 n. 1 p. 232-243 jan. |jun. 2019 


\section{- RESUMO}

O estudo visa oferecer uma leitura acerca do conceito de Teatro Rapsódico, tendo como objetivo expor as principais ideias e noções do ponto de vista teórico que formam o entendimento de rapsódia teatral. O conceito foi estabelecido pelo pesquisador teatral francês Jean-Pierre Sarrazac em $1981 \mathrm{em}$ sua tese intitulada O futuro do drama. O estudo parte dessa obra e procura sintetizar os pontos chaves de cada tópico a qual o autor se debruça. Outro material de suporte utilizado foi o Léxico do drama moderno e contemporâneo, escrito pelo grupo de estudos o qual Sarrazac frequenta e organizado por ele próprio. Em seguida, procuramos contextualizar o conceito, procurando entender sua origem e suas relações com outros estudiosos da temática do drama moderno como Peter Szondi e Jean-Pierre Ryngaert.

\section{PALAVRAS-CHAVE}

Teatro Rapsódico, drama moderno e contemporâneo, Jean-Pierre Sarrazac

\section{ABSTRACT}

The aim of the study is to offer the reader a reading about the concept of Rapsodic Theater, aiming at exposing the main ideas and notions from the theoretical point of view that form this understanding of theatrical rhapsody. The concept was established by the French theatrical researcher Jean-Pierre Sarrazac in 1981 within his thesis titled $O$ futuro do drama. It was begining from this work that the research was started, trying to synthesize the key points of each topic to which the author studies. Another supporting material used by the Léxico do drama moderno e contemporâneo, written by the study group Sarrazac attends and organizes by himself. Next, we try to contextualize the concept, trying to understand its origin and its relations with other scholars of the modern drama as Peter Szondi and Jean-Pierre Ryngaert.

\section{KEYWORDS}

Rapsodic Theater, modern and contemporary drama, Jean-Pierre Sarrazac 


\title{
1. Prévias apresentações
}

O estudo a ser apresentado visa oferecer uma leitura acerca da reflexão estabelecida pelo teatrólogo francês Jean-Pierre Sarrazac em sua tese de doutorado $O$ futuro do drama, defendida em 1981 e traduzida em Portugal no ano de 2002, ainda pouco difundida no Brasil. Na obra, o autor procura estabelecer a priori o conceito de Teatro Rapsódico, sendo ele capaz de abarcar o teatro praticado em nossa contemporaneidade, pelo menos segundo o teórico.

Esse texto está organizado em três momentos: o primeiro, sendo este, pretende situar o leitor acerca do contexto onde o conceito de Teatro Rapsódico foi estabelecido, procurando apresentar outros conceitos que ajudam no melhor entendimento deste; o segundo momento será reservado à tese de Sarrazac, sendo oferecida uma compilação das principais informações referentes ao conjunto de características que juntos formam o conceito de Teatro Rapsódico; e findando o estudo, uma reflexão acerca da leitura procurando realizar uma síntese do conceito sarrazaqueano.

Em 1956 o teatrólogo húngaro Peter Szondi publica a obra: Teoria do Drama Moderno (1880 - 1950), na qual ele explana e conceitua sobre o modelo dramático instaurado até aquele período ${ }^{1}$, o qual intitula de Drama Absoluto $^{2}$. Szondi, conclui que este modelo estaria em crise, pois não estaria mais dando conta das diferentes e complexas relações do mundo moderno, ele indica a figura do Eu-épico ${ }^{3}$ (ou sujeito épico) brechtiano como principal fator para o drama entrar em crise, e ao mesmo tempo pontua as "dramaturgias épicas de Piscator e Brecht como principais 'tentativas de solução' suscetíveis de responder à [essa] crise do drama” (KUNTZ \& LESCOT. In: SARRAZAC, 2012, p. 74).

O teatrólogo francês Jean-Pierre Sarrazac, tem outro ponto de vista acerca do drama e de seu desfecho. Ele aponta uma metamorfose do gênero que perderia seu caráter individualista ganhando uma formatação híbrida.

\begin{abstract}
O conceito do drama absoluto pode apontar para uma hibridização do épico e do dramático, do individual e do coletivo, que as estéticas do século XX não cessaram de reinventar. Pois trata-se de um modelo que exige ser perpetuamente superado e contestado. Ao "drama absoluto", podemos assim opor o "drama real", concebido não como um modelo, mas como uma noção capaz de explicar essas tentativas de superação e misturas sugeridas na história, incluindo a mais recente das formas. (KUNTZ \& LESCOT. In: SARRAZAC, 2012, p. 74-75).
\end{abstract}

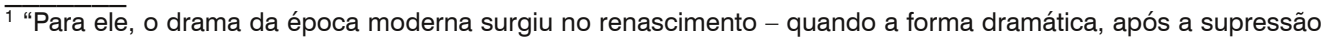
do prólogo, do coro e do epílogo, [...], encontrou do diálogo sua mediação universal. O drama que surge daí é 'absoluto', no sentido que só representa a si mesmo - estando fora dele, enquanto realidade que não conhece nada além de si, tanto o autor quanto o espectador." (PASTA JÚNIOR. In: SZONDI, 2001, p.13)

${ }^{2}$ Segundo Szondi, o drama absoluto teria "o domínio absoluto do diálogo [...] [e teria] uma dialética fechada em si mesma" (SZONDI, 2001, p.30), permitindo um desligamento total do mundo exterior do dramaturgo, do ator e do público. Além da manutenção das unidades de tempo, ação e espaço, o drama seria de ordem primária, ou seja, "não [seria] a representação (secundária) de algo (primário), mas se representa a si mesmo[...], sua ação bem como suas falas, é 'originária', e se dá no presente. Não conhecendo a citação, nem a variação" (SZONDI, 2001, p.31)

${ }^{3}$ Ator/personagem que faz uso de mecanismos que quebram o andamento linear do drama, propondo uma espécie de entrada do autor dentro da cena: O narrador.
}

ouvirouver Uberlândia v. 15 n. 1 p. 232-243 jan. |jun. 2019 
O pesquisador irá buscar no teatro do alemão Bertolt Brecht a figura do euépico, para oferecer uma abordagem diferente de Szondi. Enquanto o húngaro afirma que o surgimento dessa figura anuncia a crise do drama, Sarrazac utiliza desse sujeito no seu conceito de teatro rapsódico atribuindo a ele a "personificação" do autor dentro da dramaturgia:

No teatro épico (Brecht) as personagens tomam o lugar do seu criador e representam então o papel idêntico ao do narrador de romance: comentários, resumos, transições, canções, songs são também formas específicas da personagem-narradora. Fica impossível distinguir aquilo que pertence ao papel da personagem (o que ela pode narrar de maneira verossimilhante) e aquilo que é a transposição direta do discurso do autor. (PAVIS, 2015, p. 258).

\section{Apreciação e apontamentos em $O$ futuro do drama}

Os dramaturgos são vivamente convidados a diminuir suas velhas imposições, da forma canônica do drama. Na verdade, a modernidade da escrita resulta deste incessante trabalho rapsódico que eles realizam no corpo do drama. Devem também desviar-se do conservadorismo que pretende mumificar a obra dramática, de um modernismo que proclama ritualmente a morte do drama (ou, de acordo com uma moda atual, a sua dissolução na escrita). Porque a forma mais livre - a rapsódia - não é ausência de forma. (SARRAZAC, 1998, p. 99).

O desenvolvimento desse estudo tem início onde o conceito foi estabelecido, dentro da tese escrita pelo Sarrazac. Decidimos, então, levantar os aspectos mais relevantes do conceito de teatro rapsódico que estão inseridos dentro de $\mathrm{O} f u$ turo do drama. Tais aspectos levantam questões relativas à escrita moderna rapsódica que coloca em cheque (apontamentos de crise) as noções tradicionais de construção dramatúrgica, fábula, personagem e diálogo.

\subsection{Hibridismo}

Acabar com [...] a tirania do texto escrito sacralizado - ousar outros signos, e permitir-se dizer aquilo que nos acontece com signos que vêm do palco. Acabar (verdadeiramente e radicalmente) com a tradição de um teatro dramático da mimesis, fundado sobre a tríade "totalidade, ilusão, representação do mundo" (TACKELS, 2007, p. 2)

Sarrazac aproxima a figura histórica do rapsodo com o dramaturgo moderno: "[o] escritor-rapsodo (rhaptein em grego significa coser), que junta o que previamente despedaçou e, no mesmo instante, despedaça o que acaba de unir" (SARRAZAC, 1998, p. 11). E para traçar tal relação, mostra os elementos que transformariam um autor-rapsodo nessa figura de "costurador" do texto; ele ainda atribui a Bertolt Brecht e a seu teatro épico, o princípio dessa transformação. 
Segundo o autor, após o teatro brechtiano ganhar relevância, chegou-se a considerar que o teatro dramático tradicional seria uma forma decadente, ao passo que o épico seria uma revolução do teatro contemporâneo do período:

Brecht provocou [um verdadeiro abalo] nas bases aristotélicas do teatro ocidental, graças, sobretudo, à sua teoria de um teatro épico, onde os elementos narrativos rivalizam com os elementos dramáticos, abriu ao nosso teatro perspectivas de emancipação. [...] [entretanto] alguns autores ${ }^{4}$ acreditaram convictamente que se tratava de superar a forma dramática e de instalar completamente no domínio do épico, no teatro. [e] Por não ser objetivamente possível realizar essa superação, deixaram-se absorver pelo modelo da obra brechtiana. (SARRAZAC, 1998, p. 10).

A grande mudança, até então inovadora no teatro de Brecht, é a abertura dos procedimentos de emancipação da cena do texto. Propondo a interrupção da cena dramática com quebras de distanciamento do ator-personagem (eu-épico ou sujeito épico). A cena deixaria seu caráter enclausurado na unilateralidade em busca da multilateralidade dos fragmentos, o que propulsionou a cena híbrida e fez permitir uma maior aproximação do público com a cena.

Dessa forma, a cena híbrida acaba por responder a confrontação do dramático com o épico. E para melhor elucidar o conceito de hibridismo, Sarrazac busca uma metáfora presente na obra de Franz Kafka, que descreve de que forma deve ser observada essa nova vertente. Trata-se da parábola do cruzamento:

\begin{abstract}
Eu tenho um estranho animal, metade gatinha, metade cordeiro. Herdei-o do meu pai. Mas só se desenvolveu quando eu cresci; antes era mais cordeiro do que gato. Agora tem coisa dos dois. Do gato, tem a cabeça as garras; do cordeiro, o tamanho e a forma; dos dois, os olhos vacilantes e selvagens, o pelo macio e curto, os movimentos, que tanto podem ser saltos como rastejos. (SARRAZAC, 1998, p. 19).
\end{abstract}

Ou seja, ao observar uma obra teatral moderna, não se deve procurar classificar enquanto dramático (gato) ou épico (cordeiro), e sim observar a junção de ambos numa só forma, no formato híbrido (cordeiro-gato). Formatação essa que responde aos anseios da modernidade na linguagem dramática, pois como o avançar dos anos "o drama sentia-se apertado na pele do belo animal; seu sangue aspirava a ser misturo" (SARRAZAC, 1998, p. 20).

\title{
2.2 Montagem
}

O palco é decididamente o ponto de partida; o autor deixa de surgir como um poder de criação único e totalmente hegemônico; a fábula e o discurso deixam de constituir a gramática dominante. (TACKELS, 2007, p. 5)

\footnotetext{
$\overline{{ }^{4} \text { Sarrazac }}$ cita autores como Armand Gatti, Michel Vinaver, Michel Deutsch, Valère Novarina, Jean-Paul Wenzel, Xevier Pommeret, Paul Claudel, André Benedetto, entre outros autores também franceses e de outras nacionalidades.

ouvirouver Uberlândia v. 15 n. 1 p. 232-243 jan.|jun. 2019
} 
Iremos ressaltar nesse tópico os aspectos referentes ao modo de como a dramaturgia está sendo organizada, problematizando a hegemônica fábula e colocando em questão a montagem.

Inicialmente é traçado um embate entre as figuras do dramaturgo tradicional que, segundo o autor, "esconde-se sistematicamente por detrás das personagens; ausenta-se do seu próprio texto" (SARRAZAC, 1998, p. 21), sendo assim omisso dentro da dramaturgia. Em contrapartida, o "dramaturgo-rapsodo [...] [que] está sempre em primeiro plano para contar os acontecimentos e 'ninguém [a priori os personagens] pode abrir a boca sem que ele Ihe tenha dado previamente a palavra" (SARRAZAC, 1998, p. 21); temos assim a participação direta do autor, atribuindo opinião própria dentro do texto dramatúrgico.

Uma característica é ressaltada: o recorte, utilizado no drama como recurso principal para dar autonomia à cena. Enquanto no clássico aristotélico, respeita-se a regras das três unidades (ação, tempo e espaço) e cada cena só existe em função da outra. Aqui "a ordem cronológica é desvalorizada em benefício de uma ordem lógica, e passa-se, assim, de um sistema que imita a natureza para um sistema de pensamento" (SARRAZAC, 1998, p. 28), auxiliando, assim, no ideal de inquietar o espectador, atribuindo a ele a função de organizar o que está sendo assistido. Dando essa autonomia ao público, deixa-o livre para construir mentalmente o percurso não só das cenas, mas também do seu entendimento.

Ainda sobre fábula, é salientado cada vez mais seu empobrecimento em relação às raízes aristotélicas. Enquanto "a montagem ${ }^{5}$ não é só introduzida, como acaba também por intervir desde o início no ato criador: como embargo parcelar da realidade [...] E é reconhecida como [...] força produtiva que recorta e espaça o texto" (SARRAZAC, 1998, p. 32). Ou seja, é dado um protagonismo à montagem, nunca antes visto, tornando-a uma das peças principais em oposição ao drama tradicional.

\subsection{Personagem-Rapsodo}

Não são as palavras que me interessam no teatro. As palavras pertencem ao domínio da literatura. A natureza do teatro não é ser um ramo secundário da literatura. É a arte da carne, a arte mais próxima da vida, é a arte mais perigosa. Não existe nenhuma relação de perigo com um livro ou com a cidade, porque o que está em jogo é uma relação individual. $\mathrm{O}$ teatro faz apelo à comunidade, as suas apostas são outras, mesmo quando se trata de uma comunidade aleatória e instantânea. O teatro só é a ilustração de um livro à custa de uma mutilação. [...] Se o espectador deixa de ouvir as palavras, é porque elas se tornaram eficazes. (CASTELLUCCI apud TACKELS, 2007, p. 1)

Nesse momento Sarrazac pretende abordar questões relativas às personagens do drama moderno. Fazendo contrapontos com as configurações clássicas e demonstrando a necessidade de pensar essa figura em desmontagem ${ }^{6}$, em constante remontagem e em processo de emancipação, oferecendo a ela interpretações

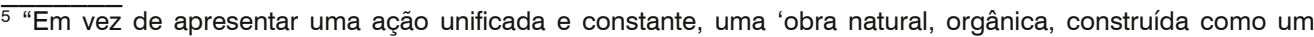
corpo que se desenvolve' (BRECHT, [...]), a fábula é quebrada em unidades autônomas.” (PAVIS, 2015, p. 249).
} 
díspares com a imagem do homem, e assim dialogar de forma mais abrangente com a sociedade moderna.

Um dos argumentos levantados pelo autor é que o teatro atual pede das personagens uma função coral, rememorando o coro grego, a personagem deve ser um recitador de ideologias, contador com propriedade de fala, visto que testemunhou todo o universo do drama ao invés da unilateralidade da visão pessoal e única. Oferecer na verdade os diferentes contextos e situações, as duas faces da moeda, que compõe todo universo dramático.

O pesquisador oferece então três tipos de personagens que seriam condizentes com o drama rapsódico:

A primeira seria a personagem-criatura ${ }^{7}$, que seria ela uma figura próxima da metamorfose do humano com o bestial, um ser híbrido; sem qualquer qualidade de protagonismo ou antagonismo, que nem oprime e nem é oprimido, sendo escravo sem mestre; e que seria capaz de retirar do público seus ideais antropocêntricos.

Após apresentar e conceituar a criatura, Sarrazac fala sobre a figura8: "personagem incompleta e discordante que se dirige ao espectador para ganhar forma: personagem a construir" (SARRAZAC, 1998, p.44). Ou seja, seria um ser fragmentado, em constante construção e que evitaria confusões entre o limite da arte e da realidade. Em alguns casos são desprovidas de nomes, gêneros ou qualquer informação que a aproximem de uma personagem humana.

Outra exemplificação de personagem atual é do Zé Ninguém ${ }^{9}$, desta vez em referência ao conceito de Wilhelm Reich. Seria ela uma figura monstruosa, vazia e autodestrutiva que no decorrer do drama iria se esfarelando até chegar a sua destruição completa.

Abarcando todos os aspectos citados, conclui-se sobre essa ideia de personagem rapsodiada:

Inacabada e desunida, a nova personagem - que abdicou da sua anterior unidade orgânica, biográfica, psicológica, etc..., que é uma personagem costurada, uma personagem rapsodeada - coloca-se a salvo do naturalismo e desencoraja toda e qualquer identificação ou reconhecimento por parte do espectador. (SARRAZAC, 1998, p. 44).

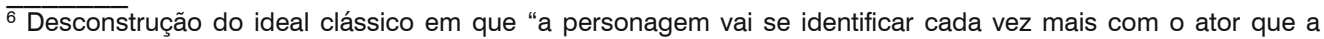
encarna e transmudar-se em entidade psicológica e moral semelhante aos outros homens, entidade essa encarregada de produzir no espectador um efeito de identificação" (PAVIS, 2015, p. 285).

7 "Uma personagem de um antropomorfismo incerto que o autor acompanharia ao longo do seu périplo teatral, cujas tribulações ele seguira passo a passo e é a qual estaria [...] indissociavelmente ligado. [...] A personagem-criatura sai do nada, no início da peça, e ao nada volta, no final. Existe, apenas, de forma paradoxal e só é viável durante o tempo da representação. Ela depende estritamente do seu criador." (SARRAZAC, 1998, p. 39).

${ }^{8}$ Sarrazac oferece algumas características do que seria a figura, baseado na obra de Samuel Beckett: "Figura humana feita em pedaços, que absorve e é absorvida, que come e é comida. Boca ou ânus, lugar de dizer.[...] A voz e o corpo desencaixaram-se. Enquanto a primeira [a voz] permanece errante no infinito da linguagem, o segundo [o corpo] parece revelar-se atônito com seu próprio aniquilamento. [...] A figura consagra, deste modo, uma perda de identidade progressiva da personagem e a sua definitiva não correspondência com o passado. O retorno biográfico de si mesmo deixou de ser possível a cada personagem beckettiana" (SARRAZAC, 1998, p. 43).

9 "Sentes-te infeliz e medíocre, repulsivo, impotente, sem vida, vazio. Não tens mulher e, e a tens, vais com ela para a cama só para provar que és homem. Nem sabes o que é o amor. Tens prisão de ventre e tomas laxantes. Cheiras mal e tua pele é pegajosa, desagradável. Nas sabes envolver o teu filho nos braços, de modo que o tratas como um cachorro em quem se pode bater à vontade. A tua vida vai andando sob o signo da impotência; é nisso que pensas, é isso que te impede de trabalhar. A tua mulher abandona-te porque és incapaz de lhe dar amor. Sofres fobias, nervosismo, palpitações...." (SARRAZAC, 1998, p.52)
}

ouvirouver Uberlândia v. 15 n. 1 p. 232-243 jan. |jun. 2019 
É possível perceber a preocupação em apontar novos modos de observar a personagem contemporânea. Tendo ela novas premissas divergentes da ideia clássica de personagem aristotélica.

\subsection{Heterogenia Linguística}

Atualmente fala-se muito de linguagem, é como se as pessoas de repente tivessem percebido que, há dezenas e dezenas de milhares de anos, elas falam. Agora, tenta-se saber o que quer dizer falar. Fazemse algumas confusões, voluntariamente ou não. Uma linguagem é um pensamento. Também é a manifestação de um pensamento. A linguagem é uma coisa, a maneira de falar é outra. A maneira de falar pode ser uma enganação. Confunde-se uma certa maneira de falar com uma linguagem certa. (IONESCO, 1967 apud RYNGAERT, 1998, p. 158).

Sarrazac procura desenvolver o estudo sobre o texto dentro do drama moderno, ou melhor, a sua formatação e sua colocação no espaço dramático. Inicia levantando a problemática da escrita da forma clássica que coloca o diálogo como forma de construção em detrimento do conflito das relações opositoras; "o diálogo desencadeia simbolicamente a ação; ele é, ao mesmo tempo, sua causa e sua consequência" (PAVIS, 2015, p. 93).

Entretanto, essa forma clássica advinda da poética aristotélica acaba por enfraquecer e alguns escritores decidem que irão escrever de outro modo, questionando essa hegemonia existente até então ${ }^{10}$. Pois, o diálogo dramático se desconstrói, adentrando numa crise onde apenas o princípio da escrita (a linguagem) consegue conceber vida nova ao teatro moderno:

Privado de sua função tradicional de formular o conflito e de o conduzir ao seu termo, através de uma série infinita de relações duais, o diálogo dramático desaparece progressivamente e enfraquece. [...] À medida que o diálogo entra em decadência e se afasta do palco, instala-se, no seu lugar, aquilo que julgávamos ser a sua substância inalienável: A linguagem. (SARRAZAC, 1998, p. 57).

Com essa nova prática, as possibilidades de escrita aumentam, é possível colocar o personagem em submissão a essa dita linguagem, pois ela pode tornar-se protagonista de um drama. É também possível criar situações utilizando uma formatação que atrasa a recepção do sentido, porém sem lhe anular; partindo de barulhos cotidianos e triviais, palavras indistintas, pontuação fraca ou inexistente, fragmentação, cortes e afins; podendo promover desde uma grande montagem linguística a inutilidades verbais, linguagens paradoxais ou perda total de sentido. $O$

\footnotetext{
${ }_{10}$ São citados os nomes de Henrik Ibsen, Anton Tchekhov, August Strindberg como propulsores da nova escrita. E o autor Samuel Beckett como belo exemplo, pois sua obra possuía um "verdadeiro compêndio de comunicação [...] [uma] comunicação circular e repetitiva. Um discurso de isolamento, cujo diálogo seria o astro morto e apenas os satélites permaneceriam acessíveis: solilóquio, monólogo, aparte e outras compulsões solitárias da linguagem" (SARRAZAC, 1998, p. 57).
} 
silêncio ou ausência pontual de escrita também é elencado como recurso da nova escrita dramática, visto que o texto perde seu protagonismo central do fazer teatral.

Para chegar a essa heterogenia, é fundamental que seja dispensado o ideal de linearidade dramática e de homogenia linguística:

Invadindo no corpo, a língua deixa de estar obrigada a mimar a natureza como quando era ainda exterior a este corpo. Emerge uma palavra desviante, monstruosa, uma palavra contra naturam [natureza em latim]. A escrita bocal - ou anal, de tal forma estas extremidades estão ligadas -, a escrita visceral propaga a rapsódia na língua [...] e mescla, ao mesmo tempo, o lírico, o épico e o dramático, assim a língua do dramaturgo-rapsodo trespassa a escrita teatral e instaura a hibridação. (SARRAZAC, 1998, p. 75).

A figura do ator-rapsodo seria o responsável por essa função de transmissão dessa nova formatação textual, que rompe com os diálogos e desfigura a língua teatral, propondo-a cada vez mais física e sem ignorar o potencial revolucionário presente nessa linguagem.

\subsection{Desvios Dramatúrgicos}

A estratégia do desvio [...] desnaturaliza, liberta a invenção teatral do jugo - da ideologia - do "vivo", emancipa a dramaturgia moderna e contemporânea do "rotineiro" (SARRAZAC, 2012, p. 64)

Sarrazac indica um fator de grande importância nessa dramaturgia rapsódica e que auxilia nessa manutenção desse gênero e ao mesmo tempo responde a insuficiência dos preceitos aristotélicos é o desvio:

[trata-se do] regresso da ficção à realidade, deixa para trás a mitologia do recuo que o autor, uma obra, deveriam assumir, com o único objetivo de preservar a ilusão do espectador, relativamente a realidade. [...] a distância trágica e a proximidade cômica, são, de uma vez por todas, confundidas; misturam-se no seio de cada peça, então em conexão. O resultado desse encaixamento do próximo e do longínquo é precisamente o desvio. (SARRAZAC, 1998, p. 77).

O desvio no drama também pode ser entendido também como uma tensão do estranho e do familiar, um exemplo notável pode ser visto em algumas peças de Bertolt Brecht que mescla e faz o recuo entre os dois polos com o Verfremdungseffekt (efeito de estranhamento ou efeito $\mathrm{V}$ ) ${ }^{11}$, causando no espectador o reconhecimento e o possível questionamento da realidade.

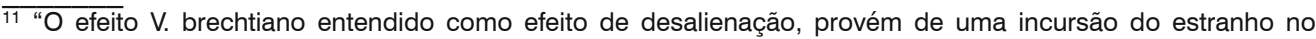
familiar. Mas, desta vez, o elemento estranho abre-nos os olhos: intrigar, espantar, suscitar uma interrogação sobre o decorrer normal dos acontecimentos através do recurso ao exagero, ao distanciamento [...] incitar, também, o espectador a um reconhecimento da realidade, eis a função do desvio" (SARRAZAC, 1998, p. 77).
} 
Em outras palavras, desviar trata-se de quebrar com a linearidade da obra para se colocar fatos ligados à realidade, dessa maneira ocorre uma economia na forma dramática. O desvio pode ocorrer de diversas maneiras, tais como a evocação de fatores externos ao drama, interrupções, abreviamentos ou semelhantes. É possível também citar exemplos de desvios que se tornaram subgêneros e que são abordados de forma singular no decorrer do capítulo: a parábola teatral, a peça histórica, o teatro de sátira e de constatação.

\title{
3. Considerações Finais: Os miúdos do Teatro Rapsódico
}

\begin{abstract}
Estamos todos de acordo quando dizemos que o século $X X$ terá visto o teatro tremer sobre as suas bases mais sólidas: arte da representação por excelência, o teatro desenvolveu, ao longo do século e das suas sucessivas vanguardas, formas que se têm transformado em profundidade, ao ponto de contestarem ao próprio teatro a função de representação do mundo. [...] Após mais de dois milênios de obediência aristotélica, o teatro já não é essencialmente construído em torno da noção de "drama" (TACKELS, 2007, p. 2)
\end{abstract}

Ao ler $O$ futuro do drama é possível perceber que o autor não se preocupou em apresentar ou elucidar sobre as vanguardas históricas do passado ou do presente. Sua intenção seria de confundir, confrontar, aproximar e afastar as teorias predominantes de sua época, para assim conceituar e expor o que seria para ele o verdadeiro drama moderno, o dito teatro rapsódico. Ele analisa essa forma de escrita dramatúrgica da modernidade, que teria novas premissas.

A primeira premissa seria estar atento à escrita dramatúrgica híbrida, que é permeada pelos diferentes gêneros (dramático, épico e lírico), transformando-se num caleidoscópio $^{12}$ teatral que mistura, além dessas diferentes classes textuais, as formas extrateatrais e não dramáticas; podendo ainda fraturar as unidades de ação, tempo e espaço; e recusar o ideal de belo animal aristotélico ${ }^{13}$. Sendo assim, resulta num outro modo poético de escrita do drama. (BRITO \& MACIEL, 2013, p. 66).

A segunda seria o estabelecimento da montagem como forma de organizar cenas, que coloca em cheque o ideal da fábula aristotélica. O uso de tal procedimento remete ao teatro praticado por Brecht e Piscator, onde a montagem seria um "recurso que permitia a utilização de um sem número de intervenções que problematizassem a cena, alterando-lhe ritmos, cronologia, estilos [...] [pois segundo Brecht] cada cena existe por si mesma [...]; [e] os acontecimentos decorrem em curvas, não linearmente." (KOUDELA \& ALMEIDA JUNIOR, 2015, p. 129-130).

O terceiro aspecto está relacionado com a personagem moderna, que pode ser chamada de rapsodo14: "enfraquecido em vários níveis, o personagem perdeu tanto características físicas quanto referências sociais; raramente é portador de um

\footnotetext{
${ }_{12}$ Caleidoscópio: 1: Aparelho de física, para obter imagens em espelhos inclinados, e que a cada momento apresenta combinações variadas e interessantes. 2: Conjunto de coisas que se sucedem, mudando. (FONTE: https://www.priberam.pt/dlpo/caleidosc\%C3\%B3pio)

13 "A beleza reside na dimensão e na ordem e, por isso, um animal belo não poderá ser nem demasiado pequeno, nem demasiado grande [...] é necessário que tenham uma dimensão que possa ser abrangia pelo olhar, também em relação aos enredos será necessária uma duração determinada, fácil de recordar. [...] [deve reunir os fatos] de acordo com o princípio da verossimilhança e da necessidade, a sequência dos acontecimentos mudando da infelicidade para infelicidade e vice-versa". (ARISTÓTELES, 2004, p. 51-52).
} 
passado e de uma história, e tampouco de projetos identificáveis" (RYNGAERT. In: SARRAZAC, 2012, p. 136). Sendo assim, muitas vezes não há preocupação em sua construção psicológica ou corporal específica, em certas obras, sequer existe a dicotomia da personagem com o ator que lhe interpreta, oferecendo ao ator autonomia dentro da cena. No que diz respeito ao trabalho do ator-rapsodo, deve haver, segundo Sarrazac, um investimento numa voz narrativa e questionadora: A dita voz rapsódica ${ }^{15}$.

O quarto ponto está ligado à quebra do diálogo entre as personagens, um dos paradigmas da escrita dramática aristotélica, o qual, na modernidade, ganhou novas formatações até pela nova personagem enfraquecida. Assim como a personagem, a fala também recebe autonomia e "não é mais necessariamente enunciada por um personagem construído, com identidade observável [...] [e] nem sempre se sabe precisamente de onde vem a fala, ou quem fala, e também não sabe a quem ela se dirige" (RYNGAERT, 1998, p.136), podendo haver um diálogo direto do autor com o espectador tendo como intermédio a encenação teatral.

A quinta e última premissa fala sobre o desvio dramático que, de certo modo, tem ligação direta com os demais aspectos da nova escrita. Que propõe que a linearidade dramática seja desviada ou quebrada em detrimento da autonomia da cena.

Partindo de tal leitura, é possível observar que a proposta do teatro rapsódico de Sarrazac estaria abdicando, ou melhor, rompendo, com a forma aristotélica tradicional que foi descrito por Szondi como Drama Absoluto.

Essa "modernidade da escrita dramática decide-se num movimento duplo que consiste, por um lado, em abrir, desconstruir, problematizar as formas antigas e, por outro, criar novas formas" (SARRAZAC, 1998, p. 10). Essa nova "forma", ou meIhor, nova nomenclatura, era até então desconhecida no teatro francês, europeu e ocidental e pode ser conceituada do seguinte modo:

A rapsódia corresponde ao gesto do rapsodo, do "autor-rapsodo" [...], que se assemelha igualmente à do costurador [...], reunindo o que previamente rasgou e despedaçando imediatamente o que acaba de juntar - a noção de rapsódia aparece, portanto ligada a saída ao domínio épico [...] e a procedimentos de escrita tais como a montagem, a hibridização, a colagem, a coralidade. (HERSANT \& NAUGRETTE. In: SARRAZAC, 2012, p. 152).

Essa nomenclatura é oriunda da Grécia Antiga e sua origem epistemológica tem como significado: Costura (rhaptein) + Poema (oide). Dessa forma trata-se de um teatro construído a partir da "costura" dos vários textos que juntos compõe a rapsódia.

\footnotetext{
$\overline{14}$ Referência ao poeta-rapsodo grego que "Capaz de executar récitas públicas das grandes epopeias homéricas, como a llíada e a Odisseia, enfatizando passagens de maior interesse para o público, que, diante de seu desempenho, poderia ir às lágrimas; também proferia espécies de conferências de caráter crítico e moral. Era-lhe garantido um grande público, diante do qual se apresentava ricamente vestido e adornado, com vistas a receber uma boa recompensa financeira, por conta de seu importante papel no sistema educacional grego antigo, a Paideia" (VIDAL-NAQUET, 2002 apud BRITO \& MACIEL, 2013, p. 66).

15 "'Voz do questionamento, voz da dúvida, da palinódia, voz da multiplicação dos possíveis, voz errática que engrena, desengrena, se perde, divaga ao mesmo tempo em que comenta e problematiza'. É uma voz desse tipo, irremediavelmente nômade e difratada, fadada à reinteração de um questionamento incessante." (HERSANT \& NAUGRETTE. In: SARRAZAC, 2012, p. 154).
} 


\section{REFERÊNCIAS}

ARISTÓTELES. Poética. Trad. Ana Maria Valente. Lisboa: Fund. Caluste Gulbenkian. 2004.

BRITO, Nayara Macêdo Barbosa de; MACIEL, Diógenes André Vieira. Das novas escritas dramatúrgicas: Aspectos rapsódicos da criação do Como se fosse [im]possível ficar aqui. Revista Conceição| Concepsion, Campinas - SP: UNICAMP - Universidade de Campinas, 2013, v.1, n.2, p. 64-77.

KOUDELA, Ingrid Dormien; ALMEIDA JÚNIOR, José Simões de. (Org.). Léxico de pedagogia do teatro. São Paulo-SP: Perspectiva. 2015.

PAVIS, Patrice. Dicionário de teatro. Trad. J. Guinsburg e Maria Lúcia Pereira, São Paulo: Perspectiva. 2015.

ROSENFELD, Anatol. O Teatro Épico. São Paulo - SP: Perspectiva. 2010.

ROUBINE, Jean-Jacques. Introdução às grandes teorias do teatro. Trad. André Telles. Rio de Janeiro RJ: Jorge Zahar. 2003.

RYNGAERT, Jean-Pierre. Ler o teatro contemporâneo. Trad. Andréa Stahel M. da Silva. São Paulo - SP: Martins Fontes. 1998.

SARRAZAC, Jean-Pierre. (Org.). Léxico do drama moderno e contemporâneo. Trad. André Telles. São Paulo: Cosac \& Naify. 2012.

O Futuro do Drama. Trad. Alexandra Moreira da Silva. 1998.

SZONDI, Peter. Teoria do drama moderno (1880-1950). Trad. Luiz Sergio Repa. São Paulo: Cosac \& Naify. 2001.

TACKELS, Bruno. Escritores de palco. Trad. Alexandra Moreira da Silva. 2007.

Recebido em 05/07/2018 - Aprovado em 10/05/2019

Como citar:

Almeida, R. (2019). O Teatro Rapsódico em miúdos. OuvirOUver, 15(2), 232-243. https://doi.org/10.14393/OUV24-v15n1a2019-16

A revista ouvirOUver está licenciada com uma Licença Creative

Commons Atribuição-NãoComercial 4.0 Internacional. 